\title{
Geological Application of HySpex Ground Hyperspectral Remote Sensing in Gold and Uranium Ore Deposits
}

\author{
Yu Sun \\ National Key Laboratory of Remote Sensing \\ Information and Image Analysis Technology \\ Beijing Research Institute of Uranium Geology \\ Beijing, China \\ e-mail: sunyutectonics@163.com
}

\section{Yingjun Zhao}

National Key Laboratory of Remote Sensing Information and Image Analysis Technology Beijing Research Institute of Uranium Geology

Beijing, China

e-mail: 13661367932@139.com

\author{
Kai Qin \\ National Key Laboratory of Remote Sensing \\ Information and Image Analysis Technology \\ Beijing Research Institute of Uranium Geology \\ Beijing, China \\ e-mail:275058337@qq.com
}

\author{
Jiangtao Nie \\ CNNC Key Laboratory of Uranium Resource \\ Exploration and Evaluation Technology \\ Beijing Research Institute of Uranium Geology \\ Beijing, China \\ e-mail: 279992936@qq.com
}

\author{
Haobo Li \\ National Key Laboratory of Remote Sensing \\ Information and Image Analysis Technology \\ Beijing Research Institute of Uranium Geology \\ Beijing, China
e-mail: $17970591 @$ qq.com \\ Beijing, China
e-mail: $17970591 @$ aq.com
}

\begin{abstract}
Hyperspectral remote sensing is a frontier field of remote sensing due to its advantage of object recognition based on spectral characteristics. This study carried out geological application of HySpex ground-based hyperspectral data at scales of both alteration belt in the Asiha gold district of Qinghai Province, and core in Xiangshan uranium deposit of Jiangxi Province. After data preprocessing, eight kinds of hydrothermal alteration minerals, such as hematite, sericite and illite, were extracted by the MTMF mapping method based on expert knowledge. Then, three alteration zones were divided in the gold deposit and six alteration zones were divided in the uranium core. The alteration minerals types, combination and distribution were further analyzed. It is concluded that alteration minerals closely related to the gold mineralization are limonite and sericite, and those closely associated with the uranium mineralization are hematite, illite and chlorite. Thus, HySpex data have a widespread prospect in basic geology survey and mineral exploration, for that their high spatial resolution can generate large-scale images, and that their high spectral resolution can identify alteration minerals.
\end{abstract}

Keywords- HySpex; alteration minerals mapping; ground-based hyperspectral; gold and uranium; geological application

\section{INTRODUCTION}

Hyperspectral data are featured by integrated images and spectra ${ }^{[1]}$.They are capable of identifying objects using meticulous spectra rather than simply discriminating them ${ }^{[2-3]}$, which is regarded as a great breakthrough, and has good application effects in the geological field ${ }^{[4-7]}$. The HySpex spectrometer used in this work is produced by Norway, and can be widely applied in airborne and ground-based studies.

At present, little geological application of HySpex data at home and abroad were conducted, and the limited application was focused on lithology classification and mineral distinguishment at scales of field and hand specimen ${ }^{[8-10]}$, and uranium alteration minerals mapping at the core scale ${ }^{[11]}$. This study mapped alteration minerals at scales of alteration belt and core, and established a processing workflow of HySpex ground-based hyperspectral data, which will provide a basis for their widespread geological application.

\section{OVERVIEW OF HYSPEX HYPERSPECTRAL DATA}

The hyperspectral data were acquired by the HySpex ground-based hyperspectral measurement system. It is composed of HySpex camera (sensor), data acquisition unit, rotation stage, rotation stage controller and tripod (Figure 1.). The sensors contain a visible to near infrared band (VNIR) sensor and a shortwave infrared band (SWIR) sensor. This measurement system can acquire ground-based hyperspectral data in the band range of 400 2500nm. 
The main technical parameters of the sensors are shown in TABLE 1. During data acquisition, weather is pretty, cloudless sky and low water vapor were available, and reference whiteboard was put within the field of HySpex sight. Reference whiteboard date was collected synchronously. In this study, hyperspectral date of alteration belt in Asiha gold deposit and a mineralized core in Xiangshan uranium deposit were taken as examples.

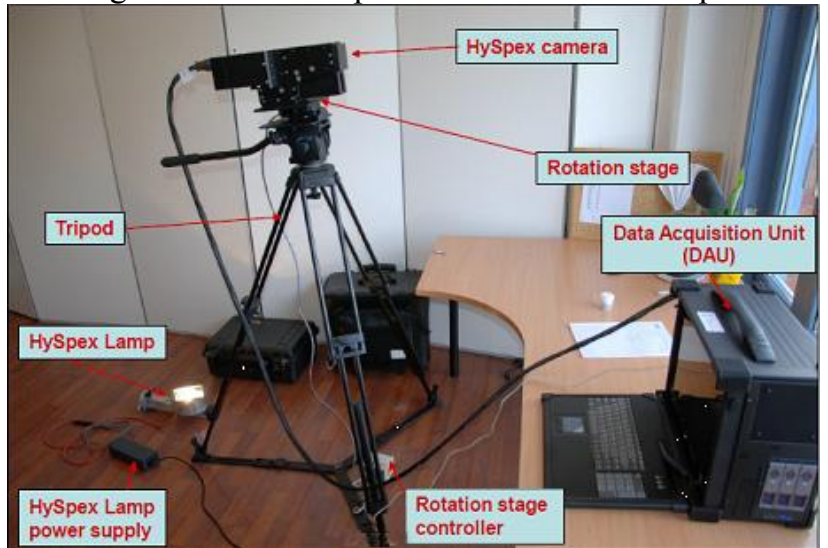

Fig .1 HySpex ground-based hyperspectral measurement system

TABLE 1. Main technical parameters of ground-based HySpex spectrometer

\begin{tabular}{|c|c|c|}
\hline $\begin{array}{c}\text { Technical } \\
\text { Parameters }\end{array}$ & Vnir-1600 & Swir-320m-E \\
\hline spectral range & $400 \mathrm{~nm} \sim 1000 \mathrm{~nm}$ & $1000 \mathrm{~nm} \sim 2500 \mathrm{~nm}$ \\
\hline spatial pixels & 1600 & 320 \\
\hline $\begin{array}{c}\text { spectral } \\
\text { sample }\end{array}$ & $3.7 \mathrm{~nm}$ & $6.25 \mathrm{~nm}$ \\
\hline $\begin{array}{c}\text { bands number } \\
\text { FOV across } \\
\text { track }\end{array}$ & 160 & 256 \\
\hline $\begin{array}{c}\text { pixel FOV } \\
\text { across/along } \\
\text { track }\end{array}$ & $0.18 \mathrm{mrd} / 0.36 \mathrm{mrd}$ & $0.75 \mathrm{mrd} / 0.75 \mathrm{mrd}$ \\
\hline digitization & $12 \mathrm{bit}$ & $14 \mathrm{bit}$ \\
\hline
\end{tabular}

\section{PRINCIPLE OF GEOLOGICAL APPLICATIONEASE}

Hyperspectral remote sensing generally has a high spectral resolution $\left(10^{-2} \lambda\right)$, and can obtain continuous and complete spectral curves ${ }^{[12]}$, aiding to the deep application of remote sensing ${ }^{[4]}$. It can identify alterations closely related to mineralization, such as greisenizag. Alteration minerals mapping is the basis of geologition, sericitization, propylitization, kaolinization, limonitization, and carbonatization. In the spectral range from $400 \mathrm{~nm}$ to $2500 \mathrm{~nm}$, absorption features of altered minerals can be essentially attributed to their physical components and lattice structures, which result from the electronic process in visible-near infrared (VNIR) bands and vibration process in shortwave infrared (SWIR) bands.

Common positive ions include $\mathrm{Fe}^{2+}, \mathrm{Fe}^{3+}$ and $\mathrm{Cu}^{2+}$, and anionic groups mainly include $\mathrm{CO}_{3}{ }^{2-}, \mathrm{Al}-\mathrm{OH}$, and $\mathrm{Mg}-$ $\mathrm{OH}^{[13]}$; both of them can be detected by the hyperspectral remote sensing technology based on spectral characteristics. Minerals with $\mathrm{Fe}^{2+} / \mathrm{Fe}^{3+}$ are hematite, limonite, chlorite, and et al. Minerals with $\mathrm{CO}_{3}{ }^{2-}$ anionic group are calcite, dolomite, and et al. Minerals with $\mathrm{Al}-\mathrm{OH}$ anionic group are sericite, illite, kaolinite, and et al. Minerals with $\mathrm{Mg}-\mathrm{OH}$ anionic group are chlorite, epidote, serpentine, and et al. The spectra of commonly hydrothermal alteration minerals in USGU spectral lib are shown below (Fig .2).

The diagnosis characteristics of minerals which contain $\mathrm{Fe}^{3+}$ locate at $870 \mathrm{~nm}$ and $350 \mathrm{~nm}$, while $\mathrm{Fe}^{2+}$ at $1000 \mathrm{~nm}$. The diagnosis characteristics of minerals which contain $\mathrm{CO}_{3}{ }^{2-}$ locate near $2350 \mathrm{~nm}$, for example, absorption peak of calcite locates at $2335 \mathrm{~nm}$ while dolomite at $2325 \mathrm{~nm}$. The diagnosis characteristics of minerals which contain Al-OH mainly locate at $2165-2215 \mathrm{~nm}$, with sub absorption peaks near that wavelength. For example, the diagnosis characteristics of kaolinite locate at $2165 \mathrm{~nm}$ and $2210 \mathrm{~nm}$. The diagnosis characteristics of minerals which contain $\mathrm{Mg}-\mathrm{OH}$ locate near $2300 \mathrm{~nm}$, as serpentine, it is at $2325 \mathrm{~nm}$. They are the basis of hyperspectral mineral reorganization. Alteration minerals can thus be accurately identified and located in hyperspectral images, and provide information for geological prospecting.

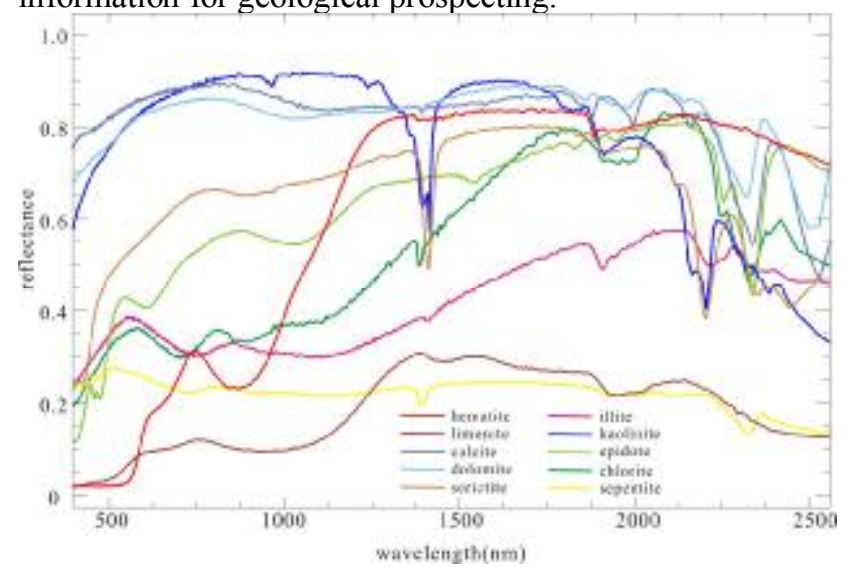

Fig .2 Spectra of commonly hydrothermal alteration minerals

\section{DATA PROCESSING}

Through repeated practice and continuous improvement, a processing workflow of HySpex data was established, as shown in Fig.3. The processing workflow includes two parts: data preprocessing, and alteration minerals mapping. Data preprocessing can provide reflectance data, which is the basis of alteration minerals mappincal analysis.

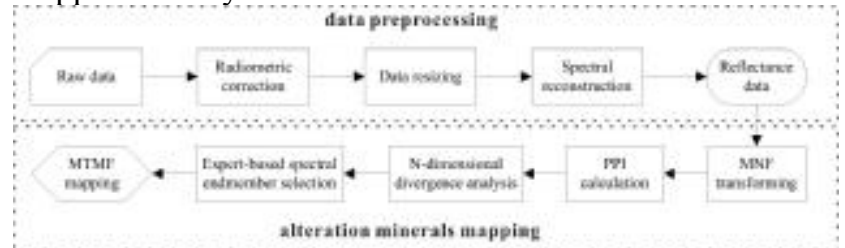

Fig .3 Processing workflow of HySpex ground-based hyperspectral data

\section{A. Data preprocessing}

Data preprocessing includes radiometric correction, data resizing and spectral reconstruction. Radiance data with the format of BIL were converted from raw data by radiometric correction. Hyperspectral data was resized by removing low signal-to-noise bands, water vapor effected 
bands, and bands not closely related to alteration mineral absorption are also eliminated. Finally, reflectance data were obtained by spectral reconstruction using the flat field method. The reference whiteboard was chosen as the flat field.

\section{B. Alteration minerals mapping}

The alteration mineral mapping was conducted by spectral hourglass process in ENVI software, which contains minimum noise fraction (MNF) transforming, pixel purity index calculation, $n$-dimensional divergence analysis and mapping method selection. Alteration minerals of hematite and limonite can be extracted using VNIR data, and those of sericite, illite, chlorite and carbonate can be acquired using SWIR data.

The selection of alteration mineral endmembers is critical in the spectral hourglass process, which directly affect the mapping results. Therefore, this study adopted synthetic analysis of spectral absorption position and overall spectral shape based on expert knowledge, and selected possible alteration mineral endmembers accordingly. It means that the endmembers should be chosen using geological background knowledge. For example, there's seldom sercite in Xiangshan uranium deposit, only illite mineral instead. Using this endmember analysis method, limonite and vegetation endmembers were found from VNIR data and three kinds of alteration minerals endmembers were selected from SWIR data in Asiha gold deposit. Meanwhile, hematite endmember was found from VNIR data and three kinds of alteration minerals endmembers were selected from SWIR data in Xiangshan uranium deposit. Endmembers to the purpose of alteration minerals mapping in SWIR data are shown below in Fig. 4.
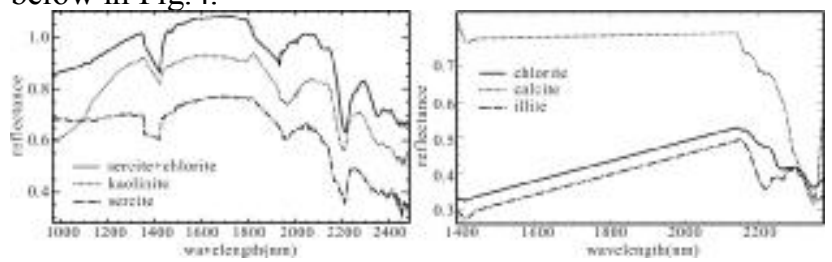

Fig .4 Endmembers used for mineral mapping in SWIR data

Mixture tuned matched filtering (MTMF) mapping method which has the advantage of low mineral detection limit. MTMF method is usually used in hyperspectral date for detecting microscope minerals. Finally, MTMF method was applied to extract alteration minerals using HySpex hyperspectral data.

\section{RESULTS AND ANALYSIS}

In this study, four kinds of alteration minerals/mineral assemblage were extracted in the Asiha gold deposit, i.e., limonite, sericite, kaolinite, and chlorite+sericite, and vegetation was also identified. Four kinds of alteration minerals were extracted from a core in the Xiangshan uranium deposit, i.e., hematite, illite, chlorite and calcite. In addition, true color images were done using HySpex hyperspectral data. Accordingly, distribution maps of alteration minerals were finished.

\section{A. Alteration analysis in Asiha gold deposit}

As shown in Fig.5, the extracted alteration minerals are limonite, sericite, sericite+chlorite, and kaolinite.
Hydrothermal alteration is mainly observed in the middle of the image, mainly in alteration zone I . Hydrothermal alteration is weak in the left of the image, which is called the alteration zone II . Alterations are generally not developed in the right part of the image, of course, it's the alteration III, with well-grown vegetation instead.

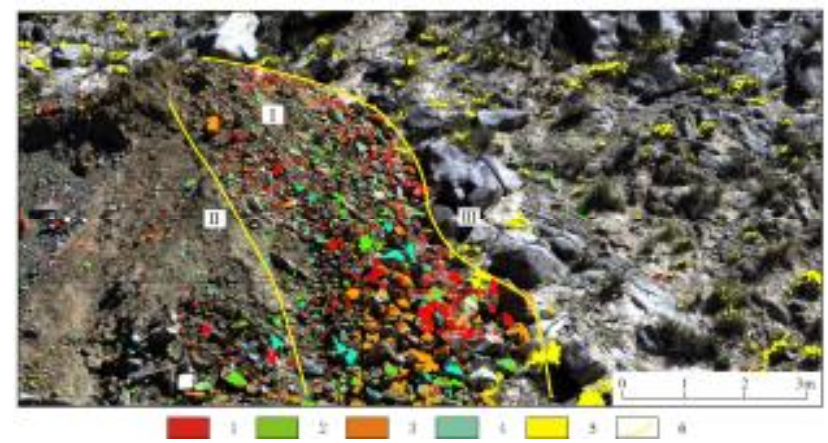

Fig .5 Distributions of alteration minerals in Asiha gold deposit

1-limonite; 2-sericite+chlorite; 3-sericite; 4-kaolinite; 5-vegetation; 6-alteration zone boundary

I -strong alteration zone; II -weak alteration zone; III seldom alteration zone

Concluded by geologist, important alteration minerals related to gold mineralization are sericite and pyrite. Gold is mostly found in pyrite, and sericite is the evidence of hydrothermal activity. Because pyrite is usually weathered to limonite which has obvious spectral characteristics in VNIR band, there are many limonite minerals in this district. In the HySpex mineral distribution map, combinations of alteration minerals closely related to gold mineralization are sericite and limonite. That's because with the reaction of hydrothermal ore-forming solution with surrounding rock, feldspar was usually altered to sericite and kaolinite; hornblende was usually altered to limonite and chlorite; pyrite closely related with gold mineralization was also oxidized to limonite in the later hydrothermal stage. Thus, the main alteration minerals in the mineralized alteration rocks mainly are sericite and limonite.

\section{B. Alteration analysis in the core of Xiangshan uranium deposit}

The distribution of alteration minerals in the Xiangshan uranium core was shown in Fig.6. It indicates that alteration is quite strong in the uranium mineralization section. Alteration near fault is the strongest, and the alteration intensity gradually becomes weak far away from fault. Alteration minerals are hematite, calcite, chlorite and illite, which generally coincide with the geological fact.

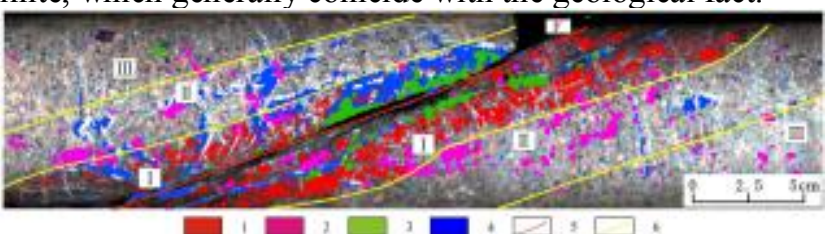

Fig .6 Distributions of alteration minerals in core of Xiagnshan uranium deposit

1-hematite; 2-illite; 3-chlorite; 4-calcite; 5-fault; 6alteration zone boundary

I -center alteration zone; II -ore-adjacent alteration zone; III -ore-near zone 
According to the alteration minerals types, combination and distribution, and combining with previous studies [14], six alteration zones were divided. Combinations of alteration minerals closely related with uranium mineralization are hematite, illite and chlorite. The alteration zone I is the center alteration zone, where rock is fragile, and phenocrysts are mostly metasomatised. The alteration minerals in zone I are hematite, illite, chlorite and calcite, where various alterations superimpose. Hematization is relatively strong in the footwall, and calcitization is relatively intense in the hanging wall. The alteration zone II is an ore-adjacent alteration zone, and the alteration minerals are illite and calcite. Illite has a distribution of crumb and punctuate, and calcite has a distribution of crumb and veined shapes. The alteration zone III is an ore-near alteration zone, and the alteration minerals are illite and calcite. Alterations in zone III are weak, and distribute dispersedly. It is worth noting that the second absorption peak of chlorite in the uranium core is near $2270 \mathrm{~nm}$, which belongs to a relatively Fe-rich chlorite ${ }^{[15]}$. It implicates that the uranium mineralization occurs in a reducing environment, which coincides with the previous studies ${ }^{[14,16]}$.

\section{CONCLUSIONS}

(1) A processing workflow of HySpex ground-based hyperspectral data was established, which involves radiation correction, data resizing, and spectral reconstruction. The spectral reconstruction technique is the flat field method using reference whiteboard as the flat field, which is suited for HySpex data.

(2) The MTMF mapping method was adopted in alteration belt of Asiha gold deposit and core of Xiangshan uranium deposit, and the endmember selection was based on expert knowledge. A total of eight alteration minerals were extracted, such as hematite, illite, chlorite and calcite. They have a great agreement with the geological data.

(3) On the basis of the alteration mineral distribution, three alteration zones were divided in gold deposit and six alteration zones were divided in uranium core. It is inferred that alteration minerals intimately related to gold mineralization are limonite and sericite, and alteration minerals closely related with uranium mineralization are hematite, illite and chlorite. Spectral characteristic analysis of chlorite shows that chlorite in uranium deposit is Fe-rich chlorite, which was formed in a reducing environment.

(4) HySpex ground-based hyperspectral data have the advantage of integrated images and spectra. Their high spatial resolution can produce images at a large scale, and the high spectral resolution can aid to extract alteration minerals accurately. These data can be widely applied to basic geology research and mineral exploration.

\section{ACKNOWLEDGMENT}

This work was financially supported by the Qinghai Provincial Geological Survey Fund (No. 2013-256), Chinese Geological Survey (No. 12120113073000), Scientific Research Fund of China National Nuclear Corporation in 2013 and Scientific Research Fund of the Department of Geology \&Mining CNNC (No. 2014-170).

\section{REFERENCES}

[1] J. Q. Peterson, G. L. Jensen, M. E. Greenman, J. A . Kristl, "Calibration of the Hyperspectral Imaging Polarimeter. Polarization: Measurement", Analysis and Remote Sensing II , 1999, pp. 296456.

[2] W. M. Baugh, W. W. Atkinson, F. A. Kruse, "Quantitative geochemical mapping of ammonium minerals in the Southern Cedar Mountains, Nevada, using airborne visible/infrared imaging spectrometer (AVIRIS)", Remote Sensing of Environment, vol. 65, 1998, pp. 292-308.

[3] Gan Fu-ping, Wang Run-sheng, Guo Xiao-fang, Wang Qing-hua, "extraction for rock and ore deposits information and prospects for application of geology using hyperspectral remote sensing-Tibet Plateau as test sample", Remote Sensing for Land \& Resources, vol. 12(3), 2000, pp. 38-44.

[4] Runsheng Wang, Shengqing Xiong, Hongfeng Nie, Shuneng Liang, Zerong Qi, Jinzhong Yang, bokun Yan, Fuyue Zhao, Jinghui Fan, Liqiang Tong, Jian Lin, Fuping Gan, Wei Chen, Suming Yang, Ruijiang Zhang, Daqing Ge, Xiaokun Zhao, Zhenhua Zhang, pinqing Wang, Xiaofang Guo, Li Li, "Remote sensing technology and its application in geological exploration", Acta Geologica Sinica, vol. 85(11), 2011, pp. 1699-1743.

[5] Qianqian Li, Xiaomei Chen, Xing Liu, Bingjing Mao, Guoqiang Ni, "Study onoil and gas exploration in sparse vegetation areas by hyperspectral remote sensing data", Chinese Optics Letters, vol. 10(S1),2012, pp. 1-4.

[6] Jing Cui, Bokun Yan, Runsheng Wang, Feng Tian, Yingjun Zhao, Dechang Liu, Suming Yang, Wei Shen, "Regional-scale mineral mapping using ASTER VNIR/SWIR data and validation of reflectance and mineral map products using airborne hyperspectral CASI/SASI data", International Journal of Applied Earth Observation and Geoinformation, vol. 33,2014, pp. 127-141.

[7] Hongrui Zheng, "Combining application of multiple spectral and hyperspectral spectral remote sensing technology in oil \&gas exploration-taking ASTER and SASI data in Jimsar area as an example", Beijing: Capital normal university, 2014, pp. 1-69.

[8] T. H. Kurz, S. J. Buckley, J. A. Howell, "Close range hyperspectral imaging integrated with terresterial Lidar scanning applied to rock characterisation at centimentre scale", International Archives of the Photogrammetry, Remote Sensing and Spatial Information Sciences, vol. XXXIX(B5), 2012, pp. 417-422.

[9] A. Baumgartner, P. Gege, C. Köhler, K. Lenhard, T. Schwarzmaier, "Characterisation methods for the hyperspectral sensor HySpex at DLR's calibration home base", http://elib.dlr.de/78685/1/SPIEBaugartner20123.pdf.

[10] R. Baissa, K. Labbassi, P. Launeau, A. Gaudin, B. Ouajhain, "Using HySpex SWIR-320m hyperspectral data for the identification and mapping of minerals in hand specimens of carbonate rocks from the Ankloute Fomation", Journal of African Earth Science, vol. 61(1), 2011, pp. 1-9.

[11] Jielin Zhang, Yanju Huang, Junhu Wang, Mi Zhou, Ding Wu, Yanxiu Xuan, "Hyperspectraldrilling core logging and 3D mineral mapping technology for uranium exploration", Uranium Geology, vol. 29(4), 2013, pp. 249-255.

[12] Qingxi Tong, Bing Zhang, Lanfen Zheng, "Hyperspectral remote sensing", Beijing: Higher Education Press, 2006, pp. 1-415.

[13] Shouxun Yan, Bing Zhang, Yongchao Zhao, Lanfen Zheng, Qingxi Tong, Kai Yang, "Summarizing the VIS-NIR spectra of minerals and rocks. Remote Sensing Technology and Application", vol. 18(4), 2003, pp. 191-201.

[14] Jian Guo, "Study on mineralization alterations of scientific deep drilling in Xiangshan uranium ore field", Beijing: Beijing Research Institute of Uranium Geology, 2014, pp.1-116.

[15] K. M. Scott, Yang Kai, J. F. Huntington, "The application of spectral reflectance studies to chlorites in exploration", Australia: CSIRO Exploration \& Mining Report 545R, 1998.

[16] Linyan Deng, "Characteristics and formation environment of Chloritization in Shazhou uranium deposit.", Nanchang: East China Institute of Technology, 2012, pp. 1-63. 